\title{
ACHIEVING THE PURPOSE OF IPA - \\ A CASE OF HIT AND MISS
}

\author{
TAMMY JOHNSON*
}

\section{Introduction}

The introduction of the Integrated Planning Act 1997 (Qld) ('IPA') saw planning law in Queensland implement extensive reform measures. The catch-cry for IPA was 'integration'.

IPA looked to provide a completely integrated development assessment system ('IDAS'). This system sought to combat the inefficiencies experienced under the previous Local Government (Planning and Environment) Act 1990 (Qld). ${ }^{1}$

Town Planning legislation in Queensland had its roots in the 1930s and until IPA the fundamental nature of the legislation had remained virtually unchanged. In its second reading speech to Parliament on 30 October $1997^{2}$ Hon. D.E. McCauley touted IPA as 'state-of-the-art planning legislation' 3 born from an increasing demand by the community to '...deliver more liveable communities and a better quality of life.' ${ }^{\prime}$ The time had arrived for change.

This paper proposes to analyse critically IPA's strengths and weaknesses in securing the following purposes -

- Accountable, efficient and co-ordinated decision-making processes;

- Lessening or avoiding adverse environmental effects of development; and

- Community involvement opportunities within the decision-making process.

* Senior Teaching Fellow, Bond University.

1 Philippa England, Integrated Planning in Queensland (2 ${ }^{\text {nd }}$ ed, 2004) 22.

2 Hon D.E. McCauley, 'Integrated Planning Bill, Second Reading Speech', (speech delivered at Queensland Parliament Legislative Assembly, 30 October 2007), 4086.

3 McCauley, ibid n 2, 4086.

4 McCauley, ibid n 2, 4086. 


\section{Accountable, efficient and co-ordinated decision-making processes}

Through IDAS, IPA was seen as the solution for improving the speed and quality of development application decision-making within State and Local Government authorities.

The aim of IPA was to streamline more than 60 assessment processes and to consolidate more than 30 pieces of legislation. ${ }^{5}$ The purpose of providing accountable, efficient and co-ordinated decision making processes is set out in s1.2.3(1)(a)(1) of IPA and is a procedural rather than substantive purpose.

As a mechanism for achieving this purpose, IPA introduced the concept of private certification for certain development applications. ${ }^{6}$ Outsourcing to private certifiers meant that the Local Governments were better equipped to focus their attention on development applications that required higher levels of assessment. This in turn promoted efficiency in the decision-making process and, it is suggested, remains a significant strength of IPA.

For the Assessment Manager to properly assess the merits of an application, various governmental departments are involved in the decision-making process. ${ }^{7}$ Some of these departments act merely as advice agencies, raising matters of concern for the ultimate consideration of the Assessment Manager. ${ }^{8}$ Others play a more important role - that of Concurrence Agency.

A Concurrence Agency has the power to insist that the Assessment Manager refuse an application. ${ }^{9}$ This power is usually given to agencies that have a role in the protection of the environment ${ }^{10}$ or community infrastructure. ${ }^{11}$

In developing a system that requires the initial identification of any relevant referral agencies, IPA through IDAS, demonstrates a strong co-ordinated approach to decision making. By integrating advice agencies into the decision-making process

5 Michael Walton, "The "Not So" Integrated Development Assessment System: Is IDAS really a 1-Stop Shop?' 2005/2006 11 Queensland Environmental Practice Reporter, 52, 66 citing the Department of Local Government and Planning Workshop 9-13 March 1998.

$6 \quad$ Integrated Planning Act 1997 (Q1d), s3.5.15(5A).

7 For example Department of Natural Resources and Water, Environmental Protection Agency, Department of Transport

$8 \quad$ Integrated Planning Act 1997 (Qld), s3.3.1.

$9 \quad$ Integrated Planning Act 1997 (Qld), s3.3.16.

10 For example, Environmental Protection Agency.

11 For example, Department of Transport. 
IDAS allows an applicant to identify and anticipate any environmental or other issues that may arise in respect of their application.

This approach allows applicants to prepare better to respond to any matters raised by referral agencies. For example, an application relating to a property that is affected by acid sulfate soils will be referred to the Department of Natural Resources and Water. Knowing this, an applicant can anticipate issues that the Department may raise by obtaining an acid sulfate soil report outlining measures that can be taken by the applicant to minimise any adverse effect caused by the disturbance of the affected soil.

In addition to co-ordination, efficiency of decision-making is demonstrated by IPA's adherence to specific time limits. IPA starts the clock ticking when an application is made ${ }^{12}$ and closely monitors its progress through the four stages of approval (Application stage, Information and Referral Stage, Notification Stage and Decision Stage). ${ }^{13}$

While IDAS provides a mechanism for a more streamlined and efficient approach to assessment of development applications, there are still many traps for the unwary developer. The IPA itself is a long convoluted Act containing many interrelated Schedules. Coupled with the Integrated Planning Regulation 1998 (Qld) ('IPR') the legislative regime is confusing and, it is suggested, could appear impenetrable to the uninitiated.

Unless applicants have a reasonable level of expertise in the area of planning and development it is virtually impossible, using IPA and IPR, to ascertain whether there are any referral agencies relevant to an application and if so, who they are. This is a weakness of IPA as it somewhat counteracts the purpose of achieving a coordinated and efficient decision-making system.

For a minor application the process that someone has to go through is just onerous. This Act seems to be fine for major development with people that are experienced in the process but if you've got mum and dad wishing to make a duplex application they just look at this and say well why bother?...14

It is important that Assessment Managers are accountable for ensuring that applications are 'properly made'.$^{15}$ It is the responsibility of the Assessment Manager

12 Integrated Planning Act 1997 (Qld), s3.2.3.

13 Integrated Planning Act 1997 (Qld), ss3.2.12, 3.3.6, 3.3.14, 3.4.5, 3.5.15.

14 Philippa England, 'Damage Control or Quantum Leap? Stakeholder Comments on the Integrated Planning Act (Qld) 1997' (1999) 8, 2 Griffith Law Review 317, 323.

15 Integrated Planning Act 1997 (Qld) s3.2.1(7). 
to examine each application to decide whether it has been properly made. Lodging an application that is not properly made could potentially land a developer in the Planning and Environment Court.

Indeed, there have been some instances ${ }^{16}$ where submitters have objected to an application asserting that it was not properly made as required by s3.2.1 of IPA. While in these instances the Court usually finds that a minor error is not fatal to an application, the resulting litigation and the additional steps to be undertaken to correct the error made result in development delays and further cost for the applicant.

Notwithstanding the excusatory power of the Court, ${ }^{17}$ some applications that are not properly made are fatal and must be made again. The limited power of the Court to excuse applications which have not been properly made is testament to the purpose of IPA to provide for accountability of decision making. Assessment Managers who receive applications that are not properly made have a responsibility to ensure that they remain accountable for decisions made.

In cases where the owner's consent has not been obtained, the Court has been firm in declaring that the Assessment Manager cannot waive the requirement, nor do the Court's excusatory powers extend to this failure. ${ }^{18}$ As a result, the failure to obtain the owner's consent will be fatal to the application. It should be noted that efficiency is one of the purposes IPA seeks to achieve.

In the context of an application where the owner's consent has not been obtained, it is suggested that the Court's excusatory power should be extended to include the ability to make orders requiring the owner's consent to be obtained rather than declaring the application void.

It is not suggested that the Court should excuse the applicant's failure to secure the owner's consent. Rather the Court should allow applicants to obtain the owner's consent, thereby remedying the error before the application can proceed. It is suggested that it is not efficient or necessary for the applicant to be required to remake the application.

Under IPA, the process that must be undertaken to identify relevant referral agencies is lengthy and complex. To work through the various items in the IPA and IPR

16 Tancred Management Pty Ltd v Brisbane City Council[2005] QPEC 035 (failure to list a referral agency); Close v Kilcoy Shire Council [201] QPELR 346 (payment of incorrect fees on application).

17 Integrated Planning Act 1997 (Qld), s4.1.5A.

18 Gold Coast City Council v Fawkes Pty Ltd [2007] QCA 444. 
Schedule 2, an applicant must have knowledge of, and access to, the mapping facilities of many Government departments. While it is acknowledged that most developer applicants engage professional advisors to prepare their development application, they must still have at least a working understanding of the legislation.

Further, the ordinary person seeking to lodge a development application will have even less chance of understanding and appreciating the complexities of IPA. The structure of IPA with its many Schedules, coupled with IPR and its many Schedules, makes navigation of the legislation difficult and confusing and is a significant weakness of IPA.

It is suggested that the Schedules be amalgamated and restricted to IPR to increase readability of the legislation. The extensive 'schedule hopping' required in order to decipher IPA causes confusion and in turn sees unnecessary errors made in applications.

In her second reading speech, Hon. D.E. McCauley emphasised the need for accountability in the decision-making process. This purpose is achieved in many ways under IPA, for example, by the clear guidelines from which infrastructure charges are levied..$^{19}$ Accountability goes hand in hand with transparency.

In this context, the Assessment Manager's decision must be based on clear criteria for assessment. This level of accountability and transparency is essential for applicants so that they know what criteria their applications are being assessed against.

This purpose is achieved, not directly through the provisions of IPA itself but rather through the many documents that make up the various Planning Schemes in Queensland. For example, the Local Area Plans, Domains and Constraint Codes used by the Gold Coast City Council set out the relevant criteria for assessment of an application.

These Planning Schemes are statutory instruments and have the force of law. ${ }^{20}$ The public is able to access the planning documents freely and easily online or at Council chambers. This high degree of accessibility ensures that the assessment criterion forming the basis of all decisions is completely transparent.

Having the assessment criteria contained in the Planning Schemes strengthens the ability of IPA to provide for an accountable and transparent decision-making process by requiring Assessment Managers to state their reasons for refusing an application

19 Integrated Planning Act 1997 (Qld) Chapter 2 Part 1; Gold Coast Planning Scheme Part 8.

20 Integrated Planning Act 1997 (Qld), s2.1.23(1). 
in the Decision Notice. ${ }^{21}$ Similarly, Decision Notices must clearly particularise any conditions that attach to an approval.22

The decisions of concurrence agencies add significantly achieving the purpose of accountability. The decisions of these agencies also form part of the final Decision Notice, providing information to the applicant as to which agency has made what decision. This information is important for applicants who wish to challenge the refusal of an application or alternatively, to challenge the validity of conditions attaching to an approval, especially if those conditions stem from advice received from a referral agency.

Further, the public availability of this information from the Assessment Manager enables the public (particularly submitters) to view the reasons for the decision and, if they are so minded, properly arm themselves before appealing the decision in the Planning and Environment Court.

\section{Lessening or avoiding adverse environmental effects of development}

The purpose of ecological sustainability is set out in s1.2.3(1)(c) of IPA and is a substantive rather than procedural purpose. Ecological sustainability is defined in s1.3.3 of IPA and recognises the importance of striking a balance between the protection of the environment, economic development and maintenance of the social welfare of communities. The definition stems from the principles expounded by the National Strategy for Ecologically Sustainable Development endorsed by the Council of Australian Governments on 7 December 1992.23

The Explanatory Notes to IPA ${ }^{24}$ state the need for intergenerational equity. This term refers to the need to ensure that future generations are provided for and considered in today's planning and development decisions.

This purpose walks the fine line between the private rights of land owners to use their land in the manner in which they see fit and the broader public policy issues of environmental protection. Marriott $v$ Maroochy Shire Council25 identified the need to protect the right of property owners to develop their land by stating that '...it is the responsibility of public bodies to take appropriate action to safeguard such areas...'.26

$21 \quad$ Integrated Planning Act 1997 (Qld), s3.5.15.

22 Integrated Planning Act 1997 (Qld), s3.5.15.

23 Integrated Planning Bill 1997 Explanatory Notes, 11.

24 Integrated Planning Bill 1997 Explanatory Notes, 13.

25 [1994] QPLR 178.

26 Marriott v Maroochy Shire Council [1994] QPLR 178 at 179-80. 
This essentially means that if the public bodies ${ }^{27}$ failed to safeguard these sensitive areas then the government should not be prohibited or restrained from approving development on that land. Notwithstanding the statement in Marriott above, to advance the purposes of IPA it is important to maintain the balance between public and private interests.

One of IPA's strengths in advancing the purpose of avoiding or lessening adverse environmental effects is the co-ordinated approach used by the various levels of government involved in the decision-making process.

For example, IPA requires applications that relate to land on which there are acid sulfate soils to be referred to the Department of Natural Resources and Water. ${ }^{28}$ This ensures that a properly qualified governmental body has the opportunity to comment on the application.

In further support of the strength of IPA's co-ordinated approach to ecological sustainability, Local Governments achieve this purpose by stating their Desired Environmental Outcomes ('DEO') clearly in their Planning Schemes. ${ }^{29}$ These planning instruments have been declared to be a statutory instrument and have the force of law. ${ }^{30}$

The DEOs relevant to the area are carefully examined by Local Government when, in its role as Assessment Manager, it considers code ${ }^{31}$ or impact assessable ${ }^{32}$ development applications.

The delegation of responsibility to Local Governments strengthens IPA's ability to secure its purpose of avoiding or lessening adverse environmental effects by ensuring that each applicable Planning Scheme incorporates appropriate measures to avoid or lessen adverse environmental effects of development. ${ }^{33}$ If the Planning Scheme is silent then the Assessment Manager is required to consider this purpose in addition to other relevant code or impact assessable considerations.

Certain applications may warrant additional scrutiny by the Assessment Manager in order properly to secure this purpose. For example, an application requiring a use

\footnotetext{
27 For example, Environment Protection Agency.

28 Integrated Planning Regulation 1998, Schedule 2, Table 3 Item 4

29 Gold Coast Planning Scheme Part 2, Division 1.

30 Integrated Planning Act 1997 (Qld), s2.1.23(1).

$31 \quad$ Integrated Planning Act 1997 (Qld), s3.5.4.

32 Integrated Planning Act 1997 (Q1d), s3.5.5.

33 Integrated Planning Act 1997 (Q1d), s2.1.3(1).
} 
that is contrary to those proposed by the Planning Scheme ${ }^{34}$ would require closer examination properly to identify whether, if the application was approved, the decision would be contrary to this purpose.

More importantly, the Assessment Manager is charged with the responsibility of refusing an application that conflicts with the DEOs for the Planning Scheme Area unless there are sufficient grounds to justify the decision despite the conflict. ${ }^{35}$

It should be noted that s6.1.4 of IPA does not require a transitional planning scheme to advance the purposes of IPA. Transitional planning schemes are documents forming a former planning scheme for a particular local government area. The documents may include maps, plans and diagrams but generally must not be inconsistent with IDAS unless specifically authorised. ${ }^{36}$

This provision is identified as a weakening of IPA's ability to secure its purposes. By allowing a transitional planning scheme to operate as if it were a planning scheme under IPA, the legislation appears to be condoning the approval of applications that could have an adverse environmental effect.

However, it is suggested that the Assessment Manager for such applications would still be compelled to refuse the application based on s1.2.2 of IPA. This particular presumption is yet to be challenged in the Planning and Environment Court however the Court has, on many occasions, stated that it will not '... usurp the role of a planning authority...'. ${ }^{37}$ While the transitional provisions may appear on first glance to be redundant given the length of time that IPA has been in force nothing could be further from the truth. Notwithstanding the provisions of s6.1.11(1) of IPA which states that all transitional planning schemes should lapse 5 years after the commencement of that section, there are still 3 local governments who have not yet put IPA planning schemes in place. ${ }^{38}$

It could be argued that by placing such a high level of responsibility on the Assessment Manager, IPA is weakening its ability to secure its environmental purpose. In response to such a proposition it should be argued that overall, IPA

34 Integrated Planning Act 1997 (Qld), s3.5.14(2)(a).

35 Integrated Planning Act 1997 (Q1d), s3.5.14(2)(b).

36 Integrated Planning Act 1997 (Q1d), s6.1.3(1).

37 Wingate Properties Pty Ltd v Brisbane City Council [2001] QPELR 272; Ecovale Pty Ltd v Gold Coast City Council [1999] 2 Qd R 35.

38 Queensland Government Gazette, Local Government, 348, 57, Miriam Vale extended to 30/9/2008; Queensland Government Gazette, Local Government, 348, 84, Belyando extended to 30/10/2008; Queensland Government Gazette, Local Government, 348, 122, Whitsunday extended to $30 / 11 / 2008$. 
shows strength of purpose by making the Assessment Manager accountable for its decision. In effect, the two purposes of accountability and environmental protection rely on each other to ensure that IPA achieves both.

In the quest to secure the outcomes sought by the environmental protection purpose the precautionary principle plays an active role. The precautionary principle applies to applications where there are '...threats of serious or irreversible environmental damage...'.39 and requires that the Assessment Manager should proceed with caution when determining the merits of such applications. ${ }^{40}$

The application of the precautionary principle acts to strengthen IPA's ability to achieve its environmental purpose by requiring closer scrutiny of environmentally sensitive applications.

In contrast to the strengths listed above, one obvious weakness of IPA is its failure to require non-Local Government referral agencies to exercise their powers in a way that 'advances IPA's purpose'. ${ }^{11}$ These referral agencies are compelled only to 'have regard to IPA's purpose'. ${ }^{42}$ This lower standard potentially operates to the detriment of the Assessment Manager.

For example, if a referral agency has 'regard to IPA's purpose' when providing advice on an application, applying that lower standard in lieu of 'advancing IPA's purpose' may see less onerous conditions placed on a Decision Notice than would otherwise have been imposed.

Alternatively, because the Assessment Manager is relying on the advice of the referral agencies, if these agencies do not apply the higher standard of 'advancing IPA's purpose' then potentially a development could be approved when it should be refused due to its failure to conform to IPA's environmental purpose.

In that regard, the Assessment Manager relies on the advice and recommendations provided by the referral agency. That government department has been determined to be the appropriate and accountable authority for determination of applications containing environmentally sensitive issues.

In order to strengthen IPA's ability to secure its purposes, it is suggested that s1.2.2 should be amended to require the Assessment Manager and all referral agencies to exercise their powers to advance IPA's purpose.

\footnotetext{
39 Integrated Planning Act 1997 (Q1d), s1.2.3(2).

40 Leatch $v$ Director-General of NPWS and Shoalhaven City Council (1993) 81 LGERA 270.

$41 \quad$ Integrated Planning Act 1997 (Qld), s1.2.2(1)(a).

42 Integrated Planning Act 1997 (Qld), s1.2.2(1)(b), (c).
} 


\section{Community involvement opportunities within the decision-making process}

Chapter 3 of IPA regulates IDAS and within that framework IPA provides opportunities for community involvement in relation to impact assessable development applications. One of the initiatives of IPA when it was first put before Parliament was to give the public more opportunities to have input into some planning and development decisions. ${ }^{43}$

Section 3.2.8 of IPA strengthens the community involvement purpose by requiring the Assessment Manager to keep and make available for public scrutiny documents relevant to each application. This in turn enables the individual members of the public and community groups to make informed submissions supporting or opposing development applications.

If a person or community group wishes to make a submission in response to a development application they may do so under s3.4.9 of IPA. Properly made submissions will be accepted from any person other than a concurrence agency. ${ }^{44}$ Other decisions under IPA that have community involvement include those relating to master planned areas, ${ }^{45}$ environmental impact statements ${ }^{46}$ and aquaculture development. ${ }^{47}$ Submitters are not required to have any proximity to or specific interest in the subject application.

One of IPA's strengths is this broad opportunity for community input however that strength is weakened by the problems related to the making of submissions. This paper previously mentioned the difficulties experienced by non-professionals ${ }^{48}$ in navigating IPA and IPR.

It is suggested that for the ordinary person who does not have any special legal or planning knowledge or expertise, the chances of mistakes occurring in the lodging of a submission is quite high. A person whose submission was not properly made ${ }^{49}$ may not have standing to appeal the decision. ${ }^{50}$ In this regard, while IPA makes community involvement possible, the practical mechanism for community members to become involved is technical and difficult.

43 Integrated Planning Bill 1997 Explanatory Notes, 4.

44 Integrated Planning Act 1997 (Q1d), s3.4.9(1).

45 Integrated Planning Act 1997 (Q1d), s2.5B.32.

46 Integrated Planning Act 1997 (Q1d), s5.8.8.

47 Integrated Planning Act 1997 (Qld), s5.8A.9.

48 A person not involved in the legal or planning industries.

49 Integrated Planning Act 1997 (Qld), Schedule 10.

$50 \quad$ Integrated Planning Act 1997 (Qld), s4.1.28(1). 
While s3.4.9 of IPA gives the public a right to lodge submissions, one must go searching through the Act and its Schedules to ascertain the correct manner in which to exercise this right. Notwithstanding this difficulty, the mechanisms and opportunities provided for public contribution strengthen IPA's ability to achieve its purpose.

Submitters are granted further rights by s4.1.28 of IPA which gives them the right to appeal to the Planning and Environment Court in response to the Assessment Manager's decision regarding a development application. The right of appeal is limited to those applications that are impact assessable, are for a preliminary approval under s3.1.6 or are made under transitional provisions that have an aspect which would have required public notification under previous legislation.

In relation to applications made under s3.1.6 for preliminary approval, IPA shows a weakness in securing its purpose for involving the community in decision-making by allowing a preliminary approval to override or vary part of the planning scheme. In this respect, a preliminary approval could result in development which would have been impact assessable (and thereby subject to public notification requirements) being downgraded to code assessable.

Allowing a preliminary approval to reduce the level of assessment required could have the effect of removing the requirement for public notification and consequently excluding the community from being involved in the decision-making process. In an attempt to counter-act any adverse effect a preliminary approval may have in regard to public involvement, IPA provides an extended notification period of 30 business days ${ }^{51}$ for preliminary approval applications.

While a preliminary approval may be advantageous for a developer proposing a large multi-staged development, a preliminary approval is not a development approval. Before any development can commence, the appropriate development approval must first be obtained. Preliminary approvals provide a beneficial mechanism for large developments to receive 'in principle' approval for their various proposed stages.

Once preliminary approval is obtained for a development the need to demonstrate the necessary uses for each stage is somewhat alleviated. In essence, the developer need only demonstrate to the Assessment Manager the future need for certain services such as child care or retail.

It is not necessary, when applying for the preliminary approval, to demonstrate current need. However, when the time comes to proceed with that stage of the

51 Integrated Planning Act 1997 (Qld), s6.7.1A(1)(c)(iii). 
development the developer must then demonstrate that the planning considerations, such as need and amenity, have been met.

Such was the case in Tower 720 Pty Limited v Hervey Bay City Council \& Anor ${ }^{52}$ where the court held that an application for an impact assessable development approval should not be granted because there was no current need for further retail premises. The court agreed with the Council that the planning scheme envisaged future retail development. In that case the appropriate remedy was to grant a preliminary approval to the developer subject to it demonstrating to the Council's satisfaction that there was sufficient need for the proposed material change of use.

Only some preliminary approvals have the effect of overriding the planning scheme. In this regard, preliminary approvals are not always as threatening as they may first appear. While there may sometimes be a decreased opportunity for community involvement, it is suggested that preliminary approvals are beneficial in providing the public with an early overview of large multi-staged developments. In this way, the public then has the opportunity to make submissions very early in the life of the development, before any actual development applications are made.

In 2006 a call for submissions was made regarding the then planned review of IPA. At that time at least one community interest group ${ }^{53}$ expressed the opinion that IPA still left much to be desired in relation to community involvement in decisionmaking. Suggestions were made in relation to the perceived shortcomings of the public notification requirement.

Among the suggestions made were increasing the number of individual notifications required to be given to owners of property in the immediate vicinity ${ }^{54}$ and requiring an applicant to advertise in all newspapers, including free papers, circulating in the area in order to increase public awareness of the application..$^{55}$

In response to this, it is suggested that the current notification requirements of IPA are sufficient. It is reasonable to expect people who live in the vicinity of a development site to become aware of the notification sign placed on the land. It is not necessary to extend notification to include owners of property in the immediate vicinity, nor is it necessary to require an applicant to become aware of, and advertise

52 [2003] QPELR 178.

53 Development Watch Inc, Coolum Beach, submission to IPA Review, DLGPSR dated 2 November 2006.

54 It was suggested that owners of all property within $100 \mathrm{~m}$ of the land should be individually notified of a development application.

55 Development Watch Inc, above n 46, 3. 
in, all newspapers circulating in the area. It is suggested that requiring more extensive notification could adversely affect an applicant, especially if they were required to advertise in all newspapers in the area.

For example, an applicant required to identify and advertise in every newspaper, including free papers, in the area may overlook the existence of a small free paper. If this occurred, the applicant would not have fallen foul of the notification requirements. This may then lead to a challenge by submitters that notification has not been properly given under IPA. Ultimately, this could lead to an application being made by the applicant, the submitters or the Council, in the Planning and Environment Court.

It is suggested that the purpose behind the notification requirements is to allow the public to become involved in the application process, not to allow them an increased number of opportunities to delay the application process on what may be a very minor discrepancy.

Further to IPA's community involvement purpose, while IPA allows the public to respond to a development application by way of submissions, it limits its ability to achieve this purpose by providing only a small window of opportunity for the public to formulate a proper response. ${ }^{56}$ Given the time frames in place under IPA, it is suggested that to extend the time allowed for public submissions by, say another five to 10 business days, would further the purposes of IPA. Having regard to the fact that the approval process usually takes 12 months or more, it is suggested that extending the submission period by another two weeks would not significantly disadvantage applicants.

\section{Conclusion}

While it is clear that IPA is not going to be run out of town any time soon, it has not yet hit the mark it was targeting. Nor, it should be noted, has it missed its point entirely. IPA rests somewhere in between those two propositions, gamely working to properly secure the advancement of its purposes as particularised in s1.2.3. For an Act that has had effect for only 11 years, it has been widely and heatedly debated by Lawyers, Planners, Developers and Community Groups alike.

Many pre-IPA professionals long for the 'bad old days' while some new-comers in the field of planning and development see IPA as an Act with 'potential and promise' ${ }^{57}$ If IPA is to achieve this potential and promise it is clear that further

$56 \quad$ Integrated Planning Act 1997 (Qld), s3.4.5(a) - at least 15 business days.

57 Michael Walton, 'Nine Years of IPA - The Good, The Bad and The Ugly', Deacons, 18 April 2007, 1, 9 . 
modification will be necessary. IPA is complex in principle and difficult to navigate in practice.

It is too cumbersome. The many Schedules in both IPA and IPR should be amalgamated into one coherent and navigable collection in order to improve readability and reduce unnecessary errors in applications and submissions.

In order to provide a fully integrated development assessment system which operates to advance the purposes of the Act, it is essential that all levels of Government involved in the decision-making process are 'reading from the same page'. One of the most significant shortcomings in IPA is its failure to require referral agencies to advance IPA's purpose. ${ }^{58}$ Well established cases such as South Australian Planning Commission $v$ Dorrestijn ${ }^{59}$ in which the South Australian Full Court found that the requirement to 'have regard' to certain matters is a requirement for the authority to '...take the stated mattes into account and consider them and give due weight to them, but without being required to comply with them...' demonstrate these shortcomings.

If IPA is to achieve its purpose of avoiding or lessening adverse environmental effects then the disparity between Assessment Managers and referral agencies must be addressed.

Community involvement has been recognised and encouraged by IPA but evidence from community groups shows that the mechanisms providing for this input need to be amended. ${ }^{60}$ It is suggested that longer notification periods to allow the public to gather the appropriate resources and information to make a fully informed submission coupled with more relaxed procedural requirements for making properly made submissions would further advance IPA's purpose of community involvement and would not adversely affect the efficiency of decision-making.

While IDAS has certainly had some impact on the co-ordination, efficiency and accountability of decision-making, there is still heavy reliance on the co-operation and co-ordination of referral agencies and Assessment Managers.

http://www.deacons.com.au/UploadedContent/NewsPDFs/Environment_Planning_article _April_2007.pdf accessed 2 July 2008

58 Integrated Planning Act 1997 (Qld), s1.2.2(1).

59 (1984) 53 LGRA 203. This decision was later reversed by the High Court but on matters not affecting this interpretation.

60 Development Watch Inc, Coolum Beach, submission to IPA Review, DLGPSR dated 2 November 2006 at page 3. 
Feedback from applicants indicates a belief that IDAS suffers from a lack of coordination..$^{61}$ Applicants lament that they are unable to contact the various referral agencies directly during the application process because they no longer know exactly who they are dealing with. ${ }^{62}$

Despite the weaknesses identified in securing its purposes, IPA nonetheless shows a marked improvement on its predecessor, the Local Government (Planning and Environment) Act 1990 (Qld). IPA is striving to achieve its objective of being 'state-ofthe-art planning legislation' ${ }^{\prime 3}$ capable of being the best performing planning regime in Australia in terms of both efficiency and quality of decisions. ${ }^{64}$ With a little more work, IPA might finally become the dynamic Act it was envisaged to be.

61 England, ibid n 14, 325.

62 England, ibid n 14, 325.

63 McCauley ibid n 2, 4086.

64 McCauley ibid n 2, 4086. 